\title{
CENTRAL RETINAL ARTERY OCCLUSION: AN UNUSUAL COMPLICATION OF SNAKEBITE
}

\author{
BHALLA A. ${ }^{1}$, JAIN A. P. ${ }^{1}$, BANAIT S. ${ }^{2}$, JAJOO U. N. ${ }^{1}$, KALANTRI S.P. ${ }^{1}$ \\ ${ }^{1}$ Department of Medicine, Mahatma Gandhi Institute of Medical Sciences, Sevagram, Wardha, \\ Maharashtra, India; ${ }^{2}$ Department of Ophthalmology, Mahatma Gandhi Institute of Medical Sciences, \\ Sevagram, Wardha, Maharashtra, India.
}

ABSTRACT. Snakebites are endemic in some parts of India, being associated with a number of complications. Ocular disturbances are rare, except for injury to the cornea or conjunctiva when the eye is directly exposed to the venom. In this work, we present a case of central retinal artery occlusion caused by snakebite.

KEY WORDS: central retinal artery, snakebite, saw-scaled viper, Echis carinatus.

\section{CORRESPONDENCE TO:}

A. BHALLA - 1032, Sector 24 B, Chandigarh, Union Territory, India. Phone: 0172-230109 Email: ashish_ritibhalla@yahoo.com 


\section{INTRODUCTION}

Snakebites are common in the tropics, increasing during the summer and rainy seasons. Complications are local or systemic. Common systemic problems can be neurologic or haematological. Ocular disturbances are rare, except for injury to the cornea or conjunctiva directly exposed to the venom. In this work, we present a rare ocular complication of viper snakebite.

\section{CASE REPORT}

A twenty-year-old housewife was bitten by a snake while sleeping. She experienced severe burning pain at the bite site and lost consciousness. The snake (saw-scaled viper, species Echis carinatus) was caught by the victim's relatives and brought to the hospital. The woman was admitted to the medical Intensive Care Unit at the Mahatma Gandhi Institute of Medical Sciences (MGIMS) - Sevagram, a rural hospital located in Vidarbha, region of Maharashtra, India. The patient regained consciousness after 20 minutes of admission. Her pulse was 100 beats per minute, and blood pressure 90/60 mmHg. Fang marks were visible at the left ankle and localized pitting oedema developed. Bleeding from the bite site was not observed. Pupils showed regular size and reaction to light. There was no ptosis, and the fundus examination was normal. She had single breath count of 34 and chest expansion of $2.5 \mathrm{~cm}$. Higher mental functions and cranial nerves examination showed no abnormalities. All reflexes were normal and plantar reflex was flexor. The patient received $100 \mathrm{ml}$ of $25 \%$ dextrose; saline solution intravenously, what improved her blood pressure; and $50 \mathrm{ml}$ of polyvalent anti-snake venom (ASV) in $200 \mathrm{ml}$ of saline solution over one hour. There was no untoward reaction to ASV. Haemoglobin and total counts were normal, and platelet count was $1.5 \mathrm{lac} / \mathrm{mm}^{3}$. Clotting time was 15 minutes and clot retraction time exceeded 30 minutes. Electrocardiogram and renal functions were normal too. At the time of admission, limb girth was 10 inches at mid-calf. Throughout the next 6 hours, it increased to 15 inches, clotting time exceeded 10 minutes and clot retraction time, 30 minutes. The patient received another $50-\mathrm{ml}$ dose of anti-snake venom without any side effects. She also received an injection of tetanus toxoid, cloxacillin and ibuprofen for pain and swelling. The woman started recovering as the swelling began to decrease and haematological parameters improved. After 24 hours of admission, she started 
complaining of diminished vision in her right eye. Pupil was semi-dilated and reaction to light was sluggish. The fundus examination provided a diagnosis of central retinal artery occlusion. Over the next few days, the patient improved clinically as her limb oedema decreased; coagulation parameters remained normal, but her vision failed to recover. The victim did not present evidences of Disseminated Intravascular Coagulation (DIC) in the form of spontaneous bleeding from any site, and the tests for fibrin degradation product (FDP) were negative. Protein C, protein S, and antithrombin III levels were normal. She was discharged from hospital after 7 days. Her vision on follow-up improved a little (6/60) but the fundus picture did not show significant alterations.

\section{DISCUSSION}

Snake venom is a complex fluid with rich components dominantly affecting the haemostatic mechanisms (5). In large doses, it can produce massive intravascular coagulation with consequent ischemic sequel to major organs (3). Toxic vasculitis caused by certain species of viper can lead to a thrombotic tendency (6). Hypercoagulation can be due to procoagulants in the venom, such as arginine, esterase and hydrolase (6), and consumption coagulopathy phase - DIC $(1,2,6)$. Hyperviscosity caused by hypovolemia may also contribute. Any inherent deficiency of protein C, protein S, and antithrombin III may manifest too (4).

Haemorrhagins are complement mediated, toxic components of Viperidae snake venom. They may result in severe vascular spasm, endothelial damage, and increased vascular permeability (2), which cause vascular occlusion and limb gangrene (6). Previous blood vessel abnormalities may also contribute to the injury. The resultant damage to major organs has been reported to affect the haematological, renal and, uncommonly, cardiovascular or neurological systems. Large vessels occlusion could be the reason for the affection of these major systems (7).

Ocular complications are rare and uncommon. However, the commonest ocular problem described for snakebite is a neurological disturbance in the form of ophthalmoplegia. Other ocular problems described for snakebite range from keratomalacia to vitreous haemorrhage, uveitis, unilateral or bilateral optic neuritis, globe necrosis, and visual loss due to cortical infarction. 
In this case, the patient had central retinal artery occlusion temporarily correlated with the snakebite. The cause of this rare complication could be the direct action of the venom toxins on the retinal artery, since coagulation abnormalities, though initially noted, improved with treatment and were absent at the time of visual loss. There was no evidence of DIC, and deficiency of protein C and S was not documented.

Central retinal artery occlusion is a rare ocular complication of snakebite that has not been reported in the literature so far.

\section{REFERENCES}

1 ARAVANIS C., LOANNIDIS PJ., KITENAA J. Acute MI and CVA in a young girl after viper bite. Br. Heart J., 1982, 47, 500-3.

2 BASHIR R., JINKIN SJ. Cerebral infarction in a young female following snake bite. Stroke, 1985, 16, 328-30.

3 CHUGH KS. Snake bite induced renal failure in India. Kidney Int., 1989, 35, 891-907.

4 KUMAR V., CORTAN RS., ROBBINS SL. Basic pathology. 5. ed. Bangalore: Prism books PVT, 1992: 69-70.

5 MARSH NA. Snake venom affecting haemostatic mechanism - a consideration of their mechanism, practical applications and biological significance. Blood coagul.

Fibrinolysis, 1994, 5, 399-410.

6 MURTHY JMK., KISHARE LT., SHANTI NK. Cerebral infarction after envenomation by Viper. J. Comput. Assist. Tomogr., 1997, 21, 35-7.

7 UPADHAYA AC., MURTHY GL., SAHAY RK., SRINIVASAN VR., SHANTARAM V. Snake bite presenting as Acute myocardial infarction, ischemic cerebrovascular accident, acute renal failure and disseminated intravascular coagulation. JAPI, 2000, 48, 1109-10. 